\title{
Solitary Plasmacytoma of Bone
}

\author{
Jianru Xiao, Wending Huang, \\ Xinghai Yang and Honglin Teng \\ The Second Military Medical University
}

China

\section{Introduction}

Solitary plasmacytoma (SP), histologically indistinguishable from multiple myeloma $(\mathrm{MM})$, is a kind of malignant tumor characterized by the proliferation of monoclonal plasma cells. SP is an independent subtype of plasmacytoma, including extramedullary plasmacytoma and solitary plasmacytoma of bone (SPB) [1]. Most solitary plasmacytomas progress to $\mathrm{MM}$, and are usually treated in the department of hematology. SPB may involve in any bone, however, it mainly occurs in the axial skeleton, especially in a vertebra. SPB has a high risk of progression to MM, and on magnetic resonance imaging (MRI) examination, at least $25 \%$ of patients with an apparent solitary lesion have evidence of disease elsewhere.

In patients with solitary plasmacytoma of bone, the diagnosis can be made in the light of clinical and radiographic manifestations combined pathology. Thereafter, systemic treatment should be performed according to the status of the patients and the evidence of disease progression [2-6].

Although definitive local radiotherapy is a choice for the treatment of SPB, no affirmative conclusion can be drawn due to the lack of randomized trials for this kind of disease. Surgical management is usually non-mandatory; however, patients may require decompression or reconstruction if there are spinal cord compression and pathological fracture.

\section{Epidemiology and clinical features}

SPB is a primary malignant tumor, mainly affecting axial skeleton, especially the vertebra[2]. These tumors occur in the spine twice as often as other bony sites [7]. The male/female ratio of SPB is about 2 to 1 with a mean age of 55 years [2]. Solitary plasmacytoma is one of the most common malignant primary tumors in spine. Involvement of the base of the skull may present with cranial nerve palsies. The early symptoms of SPB are not typical. The most common presenting symptom is pain. If spine is involved, deformity, motor deficits, sensory deficits, $\mathrm{n}$ bowel and bladder dysfunction could be seen as well as pain as result of epidural spinal-cord compression and/or instability of the vertebra. Plain radiography shows expansile, irregular osteolytic lesions with or without vertebra instability [8-9]. CT or MRI can detect the lesions and describe the tumor extent at an earlier stage. Particularly, MRI scanning has an important reference value in description of residual tumor, local relapse 
and progression to MM after treatment [10]. The presence of $\mathrm{M}$ protein has been reported in $24 \%-72 \%$ of patients [2].

\section{Radiological and laboratory features}

All patients with suspected solitary plasmacytoma should undergo X-ray examination, computed tomography (CT) scan or magnetic resonance imaging (MRI). Plain radiographs showed solitary expansile osteolytic lesion with or without collapse of the vertebral body (Fig.A). However, plain radiographs did not show any abnormality in some patients when the disease was in the early stage, thus CT scan or CT three-dimensional reconstruction examinations were needed. Most CT scan showed osteolytic lesions with or without collapse of the vertebral body or even paravertebral soft tissue masses (Fig.B). As a noninvasive technique for detecting a potential lesion of the bone, MRI has been a routine evaluation. However, there are no definitive guidelines to verify the involvement on an MRI examination. Generally, MRI shows Low or intermediate signal on T1-weighted imaging and hyperintense on T2-weighted imaging, and significant enhancement with gadolinium (Fig.C-E). Whole-body MRI may be an effective technique to detect multiple lesions but costly. MRI patterns of marrow involvement play an important role in assessment myeloma bone disease. They include normal appearance of bone marrow despite minor microscopic plasma cell infiltration, focal involvement, homogeneous diffuse infiltration, combined diffuse and focal infiltration, and variegated or "salt-and-pepper" pattern with inhomogeneous bone marrow with interposition of fat islands. It is essential to have investigations of full skeletal survey to rule out multiple lesions. It is well-known that emission computed tomography (ECT) has a primary value in detecting multiple lesions of bone. Therefore, it is recommended for patients' suspicion of multiple myeloma to undergo ECT scan, but the positive incidence of detecting occult disease is not encouraging. With the advent of positron emission tomography/computed tomography (PET-CT)[11-12], it is proved to be an important method to detect occult lesions.

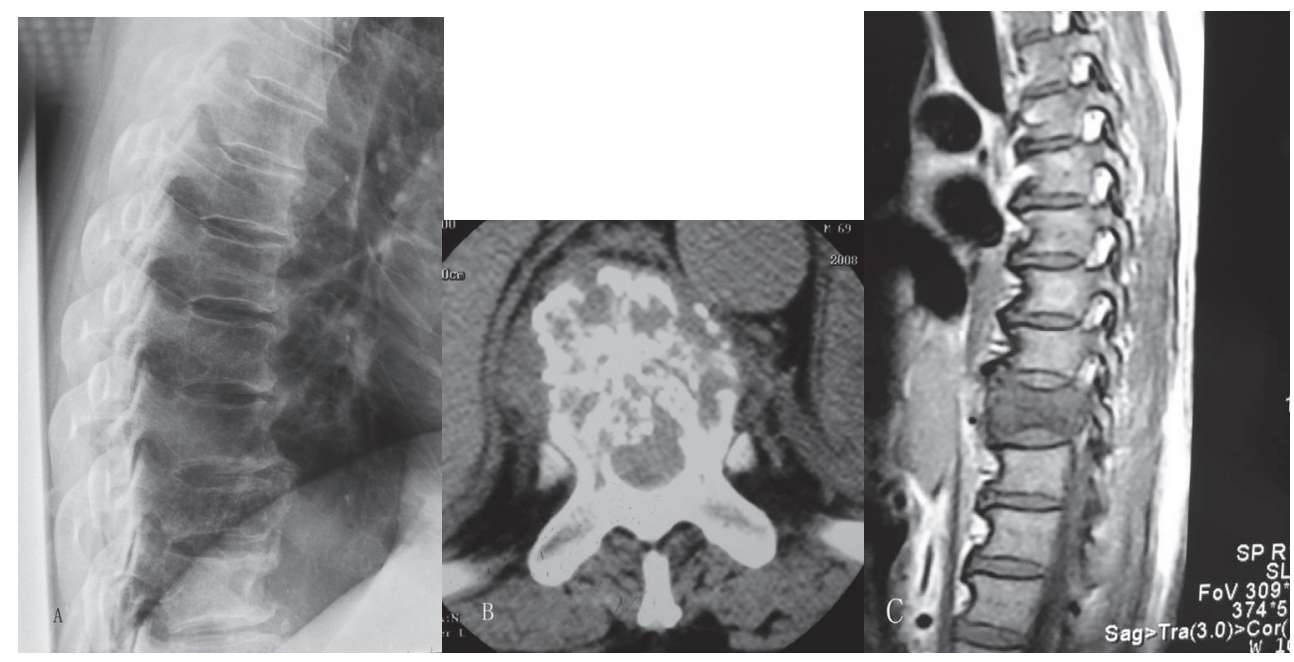




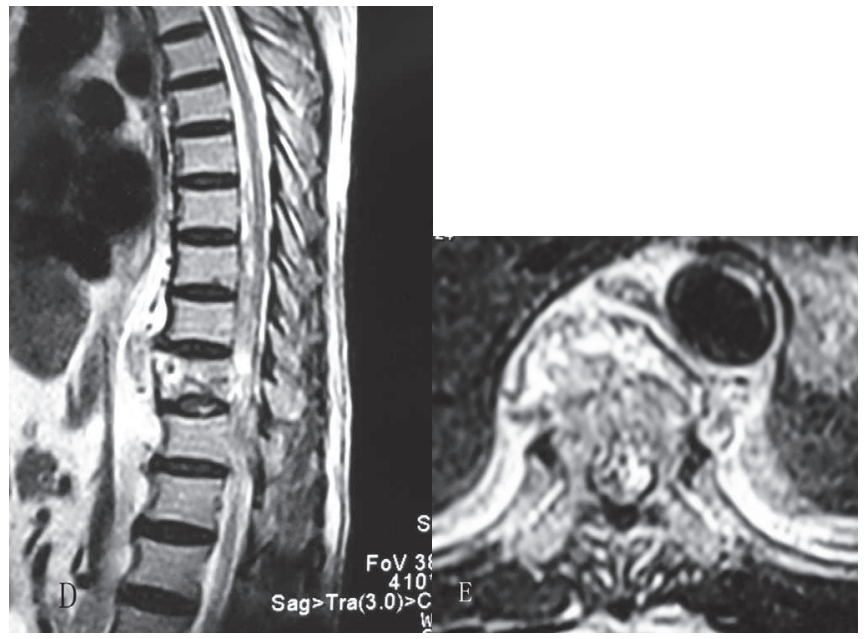

Fig. 1. A 68-year-old man with SBP of T10. Lateral radiograph showing mild collapse of vertebral body height at T10 (A).Computed tomography scan showing lytic bone destruction of the vertebral body (B). Magnetic resonance imaging showing hypointense on T1-weighted imaging $(C)$ and hyperintense on T2-weighted imaging(D), and bright enhancement after administration of gadolinium(E).

If SBP is suspected, the following laboratory investigations should be performed in all patients: complete blood count (CBC), electrolytes, immunoglobulin, serum monoclonal paraprotein (M protein) electrophoresis, urine protein electrophoresis and immune fixation, marrow cell morphology and marrow aspiration biopsy. The prevalence of a monoclonal protein (M protein) in the serum or urine of patients with SBP varies from $24 \%$ to $72 \%$, and the levels of the $\mathrm{M}$ protein $(<3 \mathrm{~g} / \mathrm{dl})$ are lower than those patients with MM [2]. In our experience, marrow aspiration biopsy is necessary to establish the diagnosis of SBP or MM with certainty.

\section{Diagnosis}

\subsection{Diagnostic criteria}

The followings are the recommended diagnostic criteria [3]:

1. A single area of bone damage due to clonal plasma cell hyperplasia.

2. Histologically normal marrow aspirate and trephine.

3. Normal results on skeletal survey, including radiology of long bones.

4. No anemia, hypercalcemia, or renal impairment due to plasma cell dyscrasia.

5. Absent or low serum or urinary level of monoclonal immunoglobulin (level of $>20 \mathrm{~g} / \mathrm{L}$ suspicious of MM).

6. No additional lesions on MRI scan of the spine.

\subsection{Biopsy and pathology}

Biopsy and histopathologic examination play an important role in diagnosing this disease. SPB is generally diagnosed by pathology. Needle biopsy under CT or fluoroscopy guidance 
can be safe and effective. As this kind of tumor is rare, it is recommended that pathology review should be performed by a senior histopathologist who is skilled in bone tumor or lymphatic system diseases. In our experience, the definitive diagnosis of SPB should be based on clinical, radiologic, and pathologic findings of patients.

\section{Treatment of solitary plasmacytoma of bone}

\subsection{Radiotherapy and recommendations}

Radiotherapy is considered the treatment of choice for solitary plasmacytoma of bone. Although high local control rates of $83 \%$ to $96 \%$ are achieved with moderate doses of radiotherapy, the progression to multiple myeloma is considerably common [6,13-17]. However, the evidence base of radiotherapy is largely consisted of retrospective studies of small series of patients. In addition, data on dose-response relationships are weak in most series of the literatures [3].

On the basis of evidences in the literatures, recommendations were put forward by oncologists $[3,5,6]$. The recommendation on the dose of radiotherapy is $40 \mathrm{~Gy}$ in 20 fractions for lesions with a margin of at least 2 centimeters. For lesions of SPB greater than 5 centimeters, a higher dose of up to 50Gy in 25 fractions should be considered. As for the extent of radiation management, the clinical target volume should include the tumor shown on MRI with a margin of at least $2 \mathrm{~cm}$. For a vertebral lesion, the scope of radiotherapy should cover the entire bone involved, together with uninvolved adjacent vertebrae $[3,8,18]$. For solitary plasmacytoma of spine, considering the anatomical specificity, more exact measurement of radiotherapy dose and target volume is needed to avoid unnecessary irritation or damage of normal tissues and neurological elements. It should include the whole involved vertebra, together with one uninvolved vertebra above and below.

\subsection{Surgery and recommendations}

Surgery is not the first choice to treat solitary plasmacytoma of bone. However, it remains a reliable option for patients with intractable pain as a result of the vertebral involvement, vertebral instability, neurological compromise, or a combination of these disorders $[3,8,9,19]$. It is the only method that leads to immediate relief of spinal compression and direct biomechanical stabilization of the involved vertebra. Indications for surgery include $[3,8,9,19,20]$ : any patient with an unstable of spine where surgery is the only way to fix and reconstruct the stabilization of spine; malignant spinal cord compression which can be alleviated by surgery; direct compression by intraspinal bony fragments; existing or impending motor dysfunction for which immediate decompression is required; no response to radiotherapy or radiotherapy tolerance and disease progressing.

The choice of surgical methods depends on the site and extent of the tumor, general condition of each patient, as well as skills and experience of surgeons. It is required that surgical plan should be designed carefully before procedure [21,22]. A gross-total resection is a reasonable choice for cervical spine tumor [23], and total en-bloc resection is feasible but challenging $[22,24]$. However, total en-bloc spondylectomy or resection is ideal for lesions in thoracic and lumbar spine and extraspinal involvements [22,24-26]. Given to the probability of long-term survival in patients with this disease, it is recommended that reconstruction of 
the involved spine should be performed $[2,8,27]$. For extraspinal osseous lesion, definitive local radiotherapy is the main treatment method. However, if pathological fractures of long bones or weight-bearing bones have been detected, surgical resection and fixation may also be required.

If surgery is required, radiotherapy should also be given. However, surgery should be carried out before radiotherapy because surgery may become more difficult in patients with preoperative radiotherapy $[2,8,28,29]$. Spinal radiation before surgery is associated with a significantly higher rate of major wound complication and may adversely affect the surgical outcome [28].

\subsection{Chemotherapy and recommendations}

Although there are insufficient data to support and advocate adjuvant chemotherapy for patients with SBP, it may be appropriate to consider to adjuvant radiotherapy in patients at higher risk of treatment failure [2-5]. Aviles et al [30] performed a prospective study which reported a benefit with combined chemotherapy and RT compared to RT alone. This study concluded that combined radiochemotherapy were likely to increase remission and survival duration. A suggested approach is to follow guidelines for the treatment of multiple myeloma [3]. In addition, patients presenting as SBP, but found on MRI to have more extensive disease, should be considered as having MM and treated accordingly [2,3,6]. In addition, bisphosphonate treatment lasting for at least one year may be benefit for patients with SBP. As for patients with MM, the bisphosphonate treatment should be prolonged to 2 years. Such management can be effective in reducing skeletal-related events [3,31-33].

\section{Natural history and prognosis}

The general prognosis of SP is comparatively better, with a 5 -year survival rate about $70 \%$ and median overall survival period of $7.5-12$ years $[2,3,34]$. There is no clear factor to predict prognosis of SP. Some researchers consider the following factors as prognosis $[3,5,17,18]$ : old age, tumor size, and persistence of $\mathrm{M}$ protein after treatment. Majority of patients probably developed MM in the end with the median time of 2-4 years, especially those with SP of spine [5,15,16-18], and approximately $15 \%-45 \%$ of patients remain disease free at 10 years[4].

However, there is still no effective method to prevent SPB from progressing to MM and there is no consensus in the literature about these adverse prognostic features. Wilder et al[36]performed a multivariate analysis on prognostic factors in a series of 60 patients and considered sustained $\mathrm{M}$ protein for over one year after radiotherapy as the adverse prognostic factor, while age, tumor size and paraprotein level were of no special prognostic value. Modalities for monitoring of disease status such as PET/CT, free light chain examination, marrow aspiration biopsy, etc. could identify high risk groups for disease progression $[3,5,6,11,12]$.

For patients with SBP, it is required carefully monitoring to detect progression to MM, possibly 6 weekly for 6 months, with extension of clinic appointments. Assessment of signs and symptoms should be undertaken, together with radiographic and laboratory investigations such as MRI, haematology, biochemistry, serum and urine paraprotein estimation $[2-6,14]$. 


\section{References}

[1] Fletcher CDM, Unni KK, Mertens F. World Health Organization classification of tumours[A]. Pathology and genetics of tumours of soft tissue and bone[M]. Lyon: IARC Press 2002;226-376

[2] Dimopoulos MA, Moulopoulos LA, Maniatis A, et al. Solitary plasmacytoma of bone and asymptomatic multiple myeloma. Blood 2000;96:2037-2044

[3] Soutar R, Lucraft H, Jackson G. Guidelines on the diagnosis and management of solitary plasmacytoma of bone and solitary extramedullary plasmacytoma. Clin Oncol 2004;16:405-413

[4] Weber DM. Solitary Bone and Extramedullary Plasmacytoma. Hematology 2005:373376.

[5] Ozsahin M, Tsang RW, Poortmans P, et al. Outcomes and patterns of failure in solitary plasmacytoma: a multicenter Rare Cancer Network study of 258 patients. Int J Radiat Oncol Biol Phys 2006;64:210-217

[6] Reed V, Shah J, Medeiros LJ, et al. Solitary plasmacytomas: Outcome and prognostic factors after definitive radiation therapy. Cancer. 2011 117:4468-4474.

[7] Chang MY, Shih LY, Dunn P, Leung WM, Chen WJ. Solitary plasmacytomas of bone. J Formos Med Assoc 1994;93:397-402.

[8] Huang W, Cao D, Ma J, et al. Solitary plasmacytoma of cervical spine: treatment and prognosis in patients with neurological lesions and spinal instability. Spine, 2010;35:E278-284.

[9] Baba1 H, Maezawa1 Y, Furusawa1 N, et al. Solitary plasmacytoma of the spine associated with neurological complications. Spinal Cord 1998; 36, 470 475

[10] Moulopoulos LA, Dimopoulos MA, Weber D, et al. Magnetic resonance imaging in the staging of solitary plasmacytoma of bone. J Clin Oncol, 1993; 11:13111315

[11] Adam Z, Bolcak K, Stanicek J, et al. Fluorodeoxyglucose positron emission tomography in multiple myeloma, solitary plasmocytoma and monoclonal gammapathy of unknown significance. Neoplasma 2007;54:536-540

[12] Orchard K, Barrington S, Buscombe J, Hilson A, Prentice HG, Mehta A. Fluorodeoxyglucose positron emission tomography imaging for the detection of occult disease in multiple myeloma. Br J Haematol 2002; 117:133-135.

[13] $\mathrm{Hu} \mathrm{K}$, Yahalom J. Radiotherapy in the management of plasma cell tumors. Oncology 2000;14:101-108

[14] Holland J, Trenkner DA, Wasserman TH, Fineberg BI. Plasmacytoma. Treatment results and conversion to myeloma. Cancer 1992;69: 1513-1517.

[15] Bolek TW, Marcus RB, Mendenhall NP. Solitary plasmacytoma of bone and soft tissue. Int J Radiat Oncol Biol Phys 1996;36:329-333.

[16] Liebross RH, Ha CS, Cox JD, et al. Solitary bone plasmacytoma: outcome and prognostic factors following radiotherapy. Int J Radiat Oncol Biol Phys 1998; 41:1063-1067 
[17] Tsang RW, Gospodarowicz MK, Pintilie M, et al. Solitary plasmacytoma treated with radiotherapy: impact of tumor size on outcome. Int J Radiat Oncol Biol Phys 2001;50:113-120

[18] Mayr NA, Wen BC, Hussey DH, et al. The role of radiation therapy in the treatment of solitary plasmacytomas. Radiother Oncol 1990;17:293-303

[19] Rao G, Ha CS, Chakrabartl I, et al. Multiple myeloma of the cervical spine: treatment strategies for pain and spinal instability. J Neurosurg Spine 2006;5:140-145.

[20] Patchell RA, Tibbs PA, Regine WF, et al. Direct decompressive surgical resection in the treatment of spinal cord compression caused by metastatic cancer: a randomized trial. Lancet 2005;366:643-648.

[21] Boriani S,Weinstein JN,Biagini R. Primary bone tumors of the spine.Terminology and surgical staging. Spine 1997;22:1036-1044.

[22] Yamazaki T, McLoughlin GS, Patel S, Rhines LD, Fourney DR.Feasibility and safety of en bloc resection for primary spine tumors: a systematic review by the Spine Oncology Study Group. Spine 2009; 34:S31-38.

[23] Barrenechea IJ,Perin NI, Triana A,et al.Surgical management of chordomas of the cervical spine. J Neurosurg Spine 2007;6:398-406.

[24] Currier BL, Papagelopoulos PJ, Krauss WE, Unni KK, Yaszemski MJ.Total en bloc spondylectomy of C5 vertebra for chordoma. Spine 2007;32:E294-299.

[25] Tomita K, Kawahara N, Baba H, Tsuchiya H, Fujita T, Toribatake Y. Total en bloc spondylectomy. A new surgical technique for primary malignant vertebral tumors. Spine 1997;22:324-333.

[26] Kawahara N, Tomita K, Murakami H, Demura S. Total en bloc spondylectomy for spinal tumors: surgical techniques and related basic background.Orthop Clin North Am 2009;40:47-63.

[27] McLain RF, Weinstein JN. Solitary plasmacytomas of the spine: a review of 84 cases. J Spinal Disord 1989;2:69-74.

[28] Ghogawala Z,Mansfield FL, Borges LF. Spinal radiation before surgical decompression adversely affects outcomes of surgery for symptomatic metastatic spinal cord compression. Spine 2001;26:818-821.

[29] Chataigner H,Onimus M,Polette A. Surgical treatment of myeloma localized in the spine. Rev Chir Reparatrice Appar Mot 1998;84:31-38.

[30] Aviles A, Huerta-Guzman J, Delgado S, Fernadez A, Diaz-Maqueo JC: Improved outcome in solitary bone plasmacytoma with combined therapy. Hematol Oncol 1996, 14:111-117.

[31] Kyle RA, Yee GC, Somerfield MR,et al. American Society of Clinical Oncology 2007 clinical practice guideline update on the role of bisphosphonates in multiple myeloma. J Clin Oncol 2007;25:2464-2472.

[32] Berenson JR, Rosen LS, Howell A, et al. Zoledronic acid reduces skeletal-related events in patients with osteolytic metastastes. Cancer 2001;91:1991-1200.

[33] Terpos E, Moulopoulos LA, Dimopoulos MA. Advances in imaging and the management of myeloma bone disease. J Clin Oncol 2011; 29:1907-1915.

[34] Dimopoulos MA, Hamilos G. Solitary bone plasmacytoma and extramedullary plasmacytoma. Curr Treat Options Oncol 2002;3:255-259. 
[35] Wilder RB, Ha CS, Cox JD, et al. Persistence of myeloma protein for more than one year after radiotherapy is an adverse prognostic factor in solitary plasmacytoma of bone. Cancer 2002; 94:1532-1537. 


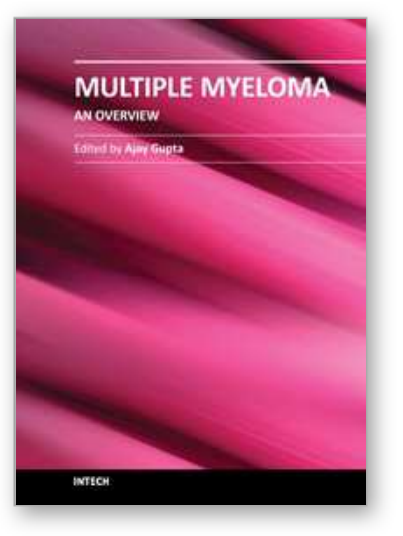

\author{
Multiple Myeloma - An Overview \\ Edited by Dr. Ajay Gupta
}

ISBN 978-953-307-768-0

Hard cover, 274 pages

Publisher InTech

Published online 20, January, 2012

Published in print edition January, 2012

Multiple myeloma is a malignant disorder characterized by the proliferation of plasma cells. Much insight has been gained into the molecular pathways that lead to myeloma and indeed much more remains to be done. The understanding of these pathways is closely linked to their therapeutic implications and is stressed upon in the initial chapters. Recently, the introduction of newer agents such as bortezomib, lenalidomide, thalidomide, liposomal doxorubicin, etc. has led to a flurry of trials aimed at testing various combinations in order to improve survival. Higher response rates observed with these agents have led to their integration into induction therapies. The role of various new therapies vis a vis transplantation has also been examined. Recent advances in the management of plasmacytomas, renal dysfunction, dentistry as well as mobilization of stem cells in the context of myeloma have also found exclusive mention. Since brevity is the soul of wit our attempt has been to present before the reader a comprehensive yet brief text on this important subject.

\title{
How to reference
}

In order to correctly reference this scholarly work, feel free to copy and paste the following:

Jianru Xiao, Wending Huang, Xinghai Yang and Honglin Teng (2012). Solitary Plasmacytoma of Bone, Multiple Myeloma - An Overview, Dr. Ajay Gupta (Ed.), ISBN: 978-953-307-768-0, InTech, Available from: http://www.intechopen.com/books/multiple-myeloma-an-overview/solitary-plasmacytoma-of-bone

\section{INTECH}

open science | open minds

\author{
InTech Europe \\ University Campus STeP Ri \\ Slavka Krautzeka 83/A \\ 51000 Rijeka, Croatia \\ Phone: +385 (51) 770447 \\ Fax: +385 (51) 686166 \\ www.intechopen.com
}

\author{
InTech China \\ Unit 405, Office Block, Hotel Equatorial Shanghai \\ No.65, Yan An Road (West), Shanghai, 200040, China \\ 中国上海市延安西路65号上海国际贵都大饭店办公楼 405 单元 \\ Phone: +86-21-62489820 \\ Fax: +86-21-62489821
}


(C) 2012 The Author(s). Licensee IntechOpen. This is an open access article distributed under the terms of the Creative Commons Attribution 3.0 License, which permits unrestricted use, distribution, and reproduction in any medium, provided the original work is properly cited. 